\title{
Multiple Views: different meanings and collocated words
}

Roberts, Jonathan C.; Al-Maneea, Hayder Mahdi Abdullah; Butcher, Peter; Lew, Robert; Rees, Geraint; Sharma, Nirwan; Frankenberg-Garcia, Ana

\section{Computer Graphics Forum}

DOI:

$10.1111 /$ cgf.13673

Published: 01/06/2019

Peer reviewed version

Cyswllt i'r cyhoeddiad / Link to publication

Dyfyniad o'r fersiwn a gyhoeddwyd / Citation for published version (APA):

Roberts, J. C., Al-Maneea, H. M. A., Butcher, P., Lew, R., Rees, G., Sharma, N., \& FrankenbergGarcia, A. (2019). Multiple Views: different meanings and collocated words. Computer Graphics Forum, 38(3), 79-93. https://doi.org/10.1111/cgf.13673

\footnotetext{
Hawliau Cyffredinol / General rights

Copyright and moral rights for the publications made accessible in the public portal are retained by the authors and/or other copyright owners and it is a condition of accessing publications that users recognise and abide by the legal requirements associated with these rights.

- Users may download and print one copy of any publication from the public portal for the purpose of private study or research.

- You may not further distribute the material or use it for any profit-making activity or commercial gain

- You may freely distribute the URL identifying the publication in the public portal ?
}

Take down policy

If you believe that this document breaches copyright please contact us providing details, and we will remove access to the work immediately and investigate your claim. 


\title{
Multiple Views: different meanings and collocated words
}

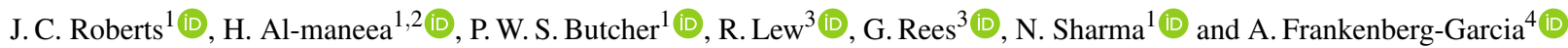 \\ ${ }^{1}$ Bangor University, UK \\ ${ }^{2}$ Basrah University, Iraq \\ ${ }^{3}$ Adam Mickiewicz University, Poland \\ ${ }^{4}$ University of Surrey, UK
}

\begin{abstract}
We report on an in-depth corpus linguistic study on 'multiple views' terminology and word collocation. We take a broad interpretation of these terms, and explore the meaning and diversity of their use in visualisation literature. First we explore senses of the term 'multiple views' (e.g., 'multiple views' can mean juxtaposition, many viewport projections or several alternative opinions). Second, we investigate term popularity and frequency of occurrences, investigating usage of 'multiple' and 'view' (e.g., multiple views, multiple visualisations, multiple sets). Third, we investigate word collocations and terms that have a similar sense (e.g., multiple views, side-by-side, small multiples). We built and used several corpora, including a 6-million-word corpus of all IEEE Visualisation conference articles published in IEEE Transactions on Visualisation and Computer Graphics 2012 to 2017. We draw on our substantial experience from early work in coordinated and multiple views, and with collocation analysis develop several lists of terms. This research provides insight into term use, a reference for novice and expert authors in visualisation, and contributes a taxonomy of 'multiple view' terms.
\end{abstract}

CCS Concepts

- Human-centered computing $\rightarrow$ Visualization; Visualization theory, concepts and paradigms; • Applied computing $\rightarrow$ Arts and humanities; Education;

\section{Introduction}

The phrase multiple views is widely used in the visualisation domain. Authors write about multiple views being displayed on the screen or laid out as small multiples, describe visualisations that have multiple levels of detail, display multivariate or multidimensional data that can be perceived from multiple perspectives. But one of the challenges for a reader is that the same phrase can have several meanings. For example, the phrase "multiple views", can be interpreted as meaning 'many opinions', 'many visual depictions' or 'alternative mathematical projections'. By contrast, different phrases can have the same sense, e.g., small multiples, trellis plots, matrix views share similar properties. Therefore, it can be confusing for an author to know how to express their ideas. Authors want to use words that their readers will understand. But novice authors or non-native speakers do not necessarily know what words to use and how to express themselves clearly. In fact, domain experts use much tacit knowledge when they write papers and articles. Expert writers know implicitly how to explain and discuss issues of multiple views, because they have gained experience with the phraseology through writing in a field, for many years. Experts know the limitations of the vocabulary, but this 'good practice' is hidden within the texts that they write. Both novices and experts can be helped through a detailed analysis and taxonomy of terms used by authors as revealed in the texts.
We present a study of terminology and phraseology used in visualisation on the topic of multiple views. Terms are single or compound words that are used within a specialised domain and have a clearly defined meaning [BP02]. Our linguistic approach informs the community and encourages them to be more careful when using words. Through such analysis, researchers in the community can have a better grasp of the breadth and expressiveness of the ideas surrounding multiple views. Our taxonomy can help users to frame their ideas and could be used to underpin the development of a wider theory of visualisation. Additionally, learners will understand better how the words are used, and they will be able to improve their writing.

We have three goals: (1) Categorise different senses of the use of 'views' in visualisation. By exploring different senses and developing a taxonomy of their meanings, we explain the diversity of word usage within this field and make authors aware of the possible ambiguities in their writing. (2) Quantify term popularity and investigate collocated words. The knowledge gained from understanding term popularity and collocated words can be used by authors to help them use suitable vocabulary for their texts. Word collocation analysis extracts words that appear close together and are statistically more frequent. For example, an academic author may write a "powerful hardware", but is less likely to write "strong hardware". Similarly, an author discussing different visualisations 
may write "multiple views" but is far less likely to talk about "multiplex views". An analysis of such usage patterns can help the community develop a common vocabulary, which in turn can help map the field and allow people outside the community to understand the domain [IIS*17]. (3) Itemise and categorise alternative terms. By exploring term diversity, we hope to encourage visualisation researchers to use these words in their writing. Our taxonomy of terms, classified by their sense, provides a reference for the community. In addition, there is potential to use these words for inspiration and creative thought, where a researcher could take one or more of the words and contemplate how they could integrate that idea in their tool design [RHR16].

\section{Background and timeliness}

It is timely to develop resources and tools that demonstrate good practices in visualisation, which can be used by expert and nonexpert users. In fact, we are seeing a democratisation of visualisation techniques where the public are using visualisations in their every day lives. Not only do we want to make sure that good practices of designing a visualisation are widely disseminated to the public, but the community must take care over the phrases and terms that they use. Much like a colour researcher would provide guidelines on developing a colourmap, and a visual designer provides guidelines for visual creation, so we should be taking the same concern of explaining best practice in written presentation.

Authors need to be mindful and purposeful in their writing, to use the correct phrases in the right contexts, and to reread, reflect and revisit their texts so as to improve them. As authors ourselves we know first-hand how difficult it can be to write well. And as researchers too, especially with a long history of research in the area of multiple views, we have personal experience of trying to correctly conceptualise the different phrases, meanings and terms in the multiple view domain. This paper has been made possible through a collaboration between visualisation experts, computer scientists and lexicographers. Indeed, we are collaborating together to develop close writing tools to help authors write better scientific texts $\left[\right.$ FGLR $\left.^{*}\right]$, where we have been focusing on collocations.

Authors need to understand both the syntactic and lexical preferences of the language, such that they can write effectively, and in a way that conforms to the expectations of the reader [FG18]. Words need to be chosen that have significance in meaning but that choice is also determined by surrounding words [Zak17]. It is through knowledge of the language that authors learn to distinguish between well-formed sentences and incorrect phrases. E.g., give advice versus $*$ give an advice, multiple views versus $*$ view multiples. Krishnamurthy [Kri87] defines collocation as "lexical items occurring ... with a greater frequency than the law of averages would lead you to expect". But collocations become more than the constituent words they represent. They take on a whole meaning themselves and imply detail that may need lengthy explanation. Furthermore, language collocations exist for no particular reason; one way is simply more popular than another. Using linguistic statistical analysis we can discover strong and weak collocations.

Our focus on multiple views is also timely because multiple view systems underpin many exploratory tools that are used by the public, research in this subject is mature, as authors we have over twenty years experience within this topic, and while researchers have provided guidelines (e.g., [WBWK00]) there are no guidelines on collocated words.

The term multiple views is a strong collocation that is found throughout the visualisation literature. The general idea is that it is useful to display data (or interpret data) in several, multiple or parallel ways. One reason a developer may incorporate many views is to make the presentation clearer. Perhaps a user better understands one style of visualisation in comparison to another, or perhaps one type of visualisation form makes it easier to perform a task, and another form makes it easier to perform a different task. For example, an alphabetic list of authors makes it easier to find a particular book by name, whereas the same data organised by price would make it easier to find the cheapest item. Whatever the field, it is often useful to display the information in a number of alternative forms, therefore multiple view principles proliferate through different application domains. This breadth of application means researchers use a variety of phrases to explain, what in essence are, very similar concepts, where terms such as juxtaposed views, side-by-side views or focus + context share similar properties. Additionally, some collocations are stronger in certain application areas, and there are opportunities for cross-fertilisation of ideas between fields.

Readers may already have an intuitive understanding of multiple views, but may not realise the breadth of the subject. They may not appreciate that there are different interpretations and senses around multiple views. For instance, developers working in storytelling will be aware that users make different conclusions from the same results [SH10], but this concept may not be understood by someone who is programming or developing coordinated visualisation tools. On the other hand, the programmer will know much more technical detail of how to code a Coordinated and Multiple View (CMV) system, but may not consider multiple interpretations. We believe, however, that to get developers to create the best possible system, they need to have a good understanding of a breadth of ideas. When researchers do realise that there is a broad set of words for this area, they may not understand what they mean or how frequently, or infrequently, they are used in practice. Therefore, part of our study focuses on words and phrases from the literature, and aims to quantify how often they are used.

\section{Related Work}

It has been a long goal of the authors to understand the diversity of phraseology in multiple views, and several key moments have led to this work. The first influence is from the large variety of related work in the area of multiple views. We start with the state of the art review of coordinated and multiple views that was published by Roberts [Rob07] in 2007. He included a large set of related words. Based on the classification of diagrams, networks, maps, charts, tables and symbols [Ber81, LRBW90] he names view types forms [Rob00b]. He writes "the words form and multiform are specific. A form is a type of visualisation (such as a parallel coordinate plot or scatter plot) while multiform is used to described that the data is displayed in two or more different forms". The word multiform has been used by several authors [GK08, MXH*03]. Roberts summarised various terms that are used within the multiple view topic, including: alternative representations, side-by-side, 
dual views, overview +detail, focus +context, difference views, master/slave, view on a bat and popup view. In addition he mentioned other layout strategies including tabular and matrix layouts. More recently, Gleicher et al. [GAW*11] classified the 1 ayout strategies as either juxtaposition, superposition and explicit encoded designs, Gleicher [Gle18] focused on comparison views, and Qu and Hullman [QH18] investigated ways to keep multiple views consistent. Several researchers provide rules over multiple-views, such as Baldonado et al. [WBWK00] suggesting to use views parsimoniously, and on the other hand Roberts' encouragement to use many views [Rob98b, Rob07].

But even before 2007, researchers were developing interactive tools that incorporate multiple views and therefore they were using a variety of phrases. In the mid 1970s, Tukey presented his interactive exploratory tool (Prim-9) that demonstrated brushing [FFT74]), which was extended by other researchers, and we get collocated phrases such as painting views [MSB90], brushing scatterplots [BC87], multiple brushes [War97], compound brushing [Che04], focus+linking [BMMS91] and angular brushing [HLD02], cross-filtered views [ Wea04] a nd implemented with the coordinated multiple view systems, such as Snaptogether [NSO0], Waltz [Rob00a] and Improvise [Wea04].

Subsequently, there are three further influences o n o ur work, each providing a different sense to the term multiple views. First, we teach computer graphics to undergraduate students, and in this domain we often use the phrase "a view", in this case we mean a particular projection. Similarly, the scientific visualisation community uses this phrase and we discover techniques such as view-dependent rendering, or view-dependent level-of-detail [Hop98]. Second, in general English we hear people say "in my view". They are talking about their opinion. Similar concepts are explored within the storytelling and narrative visualisation styles (e.g., [BLB*17]). Indeed, in our collaborative research with archaeologists [KRW*14], the archaeologists often talk about minority groups, or ways to understand the views of historic people. This is multivocality, which refers to many voices. Third, as a multidisciplinary and interdisciplinary team of authors, we have skills in, and publish across, computing, visualisation, corpus linguistics and lexicography and dictionaries, and we rely on objective evidence from text corpora to explore lexical collocation. Corpus analysis tools have developed from concordance programs of the early 1960s, open source tools such as AntConc [Ant13], to today's server-side tools. Tools such as SketchEngine [KBB*14, KK17], Wmatrix [Ray08] and CQPweb [Har12] enable bespoke corpora to be easily created. Researchers have visualised corpus data in a variety of ways, from tag clouds [AC08], dependency diagrams [CLD11a], trees [ZCCB12] to parallel coordinate plots (PCP) [CLD11b].

We focus, however, on word collocations [FG18] to explore how words combine in academic English. This work extends and develops from our early workshop paper [RFGL*18]. Word analysis is a broad topic, ranging from co-citation analysis, word frequency analysis to topic analysis, but has not frequently been applied to the visualisation field. W here there i s p rior w ork it $h$ as focused on domain analysis (e.g., [JZ16, KZC16]). The closest studies to our work are on the notion of "overview" [HH11], Isenberg et al. [IIS*17] on visualisation paper keywords, and Liu et al. [LGF*14] on co-word analysis of the human-computer interaction literature.

\section{Methodology}

We use a variety of corpus analysis strategies to perform the research, which we will explain in each section, but in summary: we started with key terms that we gathered from seminal research papers in multiple views (as explained in Section 3). This gave us an initial set of keywords. We then categorised dictionary senses of the word "view" (see Section 5) and identified five core ideas. We used this structure to classify the word list (see Table 6). We built four bespoke corpora and investigated word frequencies and term collocations. We used case-insensitive searches (e.g., a search for view finds view, View, VIEW), and we searched for word lemma forms. For example, a search for "view" will find the following lexemes: view, views, viewing, etc. Our searches are also neutral to spelling alternatives, e.g., we treat visualisation the same as visualization.

Our four bespoke corpora were built from hundreds of academic research papers (see Table 1), using the English Penn Treebank part-of-speech tagset and SketchEngine [KBB*14] software. Each of the corpora was used for different tasks. To investigate specific multiple view words, we created a corpus from 25 papers published in the CMV conference series (vCMV). To investigate words from the broad visualisation community we created a corpus of words from the list of visualisation titles and abstracts [IHK*17] (vTA). To explore how terms are used by visualisation authors, we created a large corpus containing all IEEE VIS TVCG published papers from 2012 to 2017 inclusive (v6Y). This set of papers was chosen because all the papers are on visualisation, were readily accessible, and had a rigorous publication process. In order to investigate differences in phraseology of visualisation authors in comparison to academic writers from other domains we use a fourth corpus (our reference corpus) created from Open Access Journals (doaj.org). This was chosen because it has over 2.6 billion words from nearly three million articles, over a breadth of fields including science, social science, medicine, technology and humanities.

Throughout this article we will refer to the lemma. This is an indicative word that represents inflected word forms that make up the paradigm of a given word. For example, the lemma "go", would include "going", "goes", "gone", "went". We choose this term to represent other words, and in Table 7 we include an example of its use from the v6Y corpus. We use these lemmas to calculate term frequencies and collocated words [KBB* 14$]$. Collocations provide a way to investigate habitual juxtaposition of words. For example, from a general language corpus when searching for the word drink we may find instances drink juice, drink coffee and drink tea. There is evidence that juice, coffee and tea are similar, and share the collocated verb drink. We widen the context of a lemma, by using a collocation window of five words to investigate wider collocated terms. E.g., with a lemma views and a wider context of multiple, we find multiple views, and multiple coordinated views, multiple linked views and phrases such as "the two views are coordinated through user interactions". In addition, we include examples from the literature (see Tables 3 and 7) with lemma in red.

\section{Senses of the word "view" (goal 1)}

To investigate word senses we turned to the Macmillian English Dictionary (MED) and the Oxford English Dictionary (OED) 
Table 1: We built several corpora; from the CMV series ( $v C M V)$, Titles and abstracts (vTA) [IHK* 17], 6 years of IEEE VIS TVCG (v6Y) and Open Access Journals (oAJ).

$\begin{array}{lrrrr}\text { Name } & \text { Documents } & \text { Tokens } & \text { Words } & \text { Lemmas } \\ \text { vCMV } & 25 & 177776 & 141314 & 8827 \\ \text { vTA } & 1 & 311895 & 282619 & 13617 \\ \text { v6Y } & 632 & 8223466 & 6303737 & 103775 \\ \text { oAJ } & 659132 & 3349931737 & 2662763697 & 11374691\end{array}$

(www.oed.com) of over 600,000 words. View has many senses in English, for instance the OED has a list of 18 principal senses and several minor descriptions. But many meanings are very similar, and they are too minor for our purpose. To reduce the quantity, we used affinity diagramming. Taking sentences from the v6Y corpus, we placed them on sheets of paper on a table, and through discussion investigated how they grouped together. We consolidated the possibilities into five categories, which we label $a$ to $e$ (we use this convention throughout the paper). The ordering (a to e) is suitable, because they follow the logical steps of the dataflow model [UFK ${ }^{*} 89$, HM90]. In the dataflow model users begin by thinking about the problem and framing the idea, make decisions about the data and visual mappings. This strategy is also employed by other researchers in this domain (e.g., see $\left[\mathrm{GAW}^{*} 11\right.$, Gle18, Rob00b]).

Sense a. (manner) A view is a particular manner or way of considering or regarding a subject. "The goal of dataset-centric techniques is to provide a holistic view on how the input data are processed by the network" [ $\left.\mathrm{PHG}^{*} 18\right]$. For example, designers need to consider alternative design ideas, and evaluate how to consider the challenge, think about the user and the environment [RHR17], and decide the system requirements. Multiple views and different designs can be investigated by looking at the challenge from several standpoints [NKF94, Rei85], or by framing the problem in alternative ways [KMH06, KPRP07].

Sense b. (data) A view is a selection of data from a database. It is data generated by a database in response to a query applied to existing tables, allowing the user to select what data is displayed and how it is ordered. "Each widget provides data views with multiple tabs providing different information to the users" $\left[\mathrm{MEV}^{*} 14\right]$. For example, developers can generate $\mathrm{mul}$ tiple (data) views by loading a different dataset, using a new database query or applying various filter or enhancement operations. In dataflow terminology this is a fan-out.

Sense c. (picture) A view is a pictorial representation, it is a way in which a piece of text or graphics is displayed on a computer screen. "OpinionFlow allows us to view the overall opinion distribution .. over time" [WLY*14]. For example, multiple views are observed when the data is displayed in different visualisation types (perhaps as side-by-side views), or by changing the transfer function [Rob07].

Sense d. (projection) View is the ability to see something from a particular location. "Examples include view projections (pan and zoom settings, 3D camera viewpoint)" [JD13]. For example, a designer or developer can create multiple views of a 3D design by changing the projection technique [MA83], or adapting the centre of projection [Har94].

Sense e. (opinion) A view is a personal opinion, interpretation, be- lief or attitude about a particular subject. "Different domain experts have different views of these cultural entities based on their expertise and disciplines" [ZKL*13]. "From this view point, the overview visualization does not only convey the overall picture of opinion distribution and diffusion patterns.." [WLY*14]. For example, users can have differing views or opinions on the visual depiction or the subject; they can also make different conclusions by misinterpreting results [TB95], or have different stories to tell [SH10].

\section{How frequently are multiple and view used? (goal 2)}

Our assumption is that multiple and view are used more frequently in the corpora of visualisation papers. If we are to use our corpora to analyse the ideas underpinning multiple views then we need to confirm that they are representative for our task. To perform our analysis we investigated raw frequencies and calculated normalised values (per million words) on multiple and view as headwords in vTA and v6Y, and in our reference corpus oAJ. Table 2 shows a summary of our results, confirming our hypothesis: that multiple and view are used more frequently in visualisation texts in comparison to other academic articles. To additionally confirm this analysis, we looked at other words. Obviously, the word visualisation should be more frequent in a corpus from visualisation texts (it is over two hundred times more likely to occur). But we also confirmed that many words were found in similar proportions in all corpora; words such as possible, theory, motivation and practice are equally likely to occur in any academic text (see Table 2). We also looked at term consistency over years. We found that most terms were spread through the years and included in different papers, and as expected validity diminishes with term frequency. Arranging the papers by year and alphabetically by first author, by plotting one dark line for every occurrence of that phrase, we observe word distribution over time, e.g., multiple coordinated views |||||||||||||||||||||| | , side-by-side views | ||| ||| |||| , and multiple perspectives || || ||| ||

Table 2: Part of speech (PoS) for multiple and view highlighting they are more frequent in the visualisation corpus (v6Y) in comparison to the Open Access Journal corpus (oAJ). Normalised per-million frequencies pm are shown. The non-visualisation words (possible, theory, motivation, practice) show similar proportions across corpora. Relationships between PoS are highlighted.

\begin{tabular}{lrrrr|r} 
Lemma & $P o S$ & $v T A_{p m}$ & $v 6 Y_{p m}$ & $o A J_{p m}$ & $\frac{v 6 Y}{o A J}$ \\
\hline multiple & $\mathrm{adj}$ & 1173.47 & 610.93 & 214.60 & 2.84 \\
multiple & $\mathrm{n}$. & 134.66 & 82.56 & 13.88 & 5.94 \\
relationship between & PoS: & 8.7 & 7.4 & 15.5 & \\
\hline view & $\mathrm{n}$. & 1481.26 & 1391.14 & 139.07 & 10.00 \\
view & $\mathrm{v}$. & 160.31 & 120.50 & 42.58 & 2.82 \\
relationship between & PoS: & 9.2 & 11.5 & 3.3 & \\
\hline visualization & $\mathrm{n}$. & 10654.22 & 5140.53 & 21.23 & 242.13 \\
\hline possible & $\mathrm{adj}$. & 420.01 & 443.73 & 342.57 & 1.29 \\
theory & $\mathrm{n}$. & 285.35 & 162.94 & 135.55 & 1.20 \\
motivation & $\mathrm{n}$. & 16.03 & 32.22 & 27.65 & 1.16 \\
practice & $\mathrm{n}$. & 201.99 & 154.07 & 149.93 & 1.02
\end{tabular}

\subsection{What parts of speech are used for multiple and view?}

Usage patterns and meanings change depending on the Part of Speech (POS). In each of our corpora, we discovered that multi- 
Table 3: Part Of Speech examples for multiple and view in v6Y.

adj. colour to link information across multiple views [KPV*18]

adj. understanding the relationships among multiple objects [Gle18]

n. many works use small multiples [FDC*18]

n. employs a geographical map and small multiples of [SZY*18]

n. the viewer wants to change to a view that is [SG18]

n. similarities and differences across views is [QH18]

v. participants had to view the data [BSB*18]

v. ... are generally viewed in imperfect environments [Sza18]

ple as an adjective is used seven times more than as a noun, see Table 2. In the oAJ corpus, the adjective form is more frequent, being over 15 times more common than the noun form, with multiple as an a noun being used less frequently. Our hypothesis is that adjective/noun use in the visualisation literature is closer together because of the phrase small multiples. To investigate we looked at the bigram small multiples. Out of the 679 instances of multiple as a noun in v6Y we find 323 (51.2 per million) with the phrase small multiples. The remaining bigrams are varied and include progressive multiples, $3 D$ multiple, nearest multiple [of ten], [in the] $X$ multiple (where $\mathrm{X}$ refers to a specific visualisation type); whereas only 33 (0.01 per million) cases of the bigram small multiples were found in oAJ. This analysis supports the case that small multiples are far more likely to occur in a visualisation context. Table 3 shows several example sentences for multiple and view, and their part of speech from the visualisation literature.

The word view as a noun occurs 11.5 times more often than as a verb (see Table 2), yet only 3.3 times more often in the oAJ corpus. This supports our hypothesis that the word view is used more frequently in visualisation texts than other publications. But also, authors write more frequently about a view as a visual depiction, rather than an alternative meaning of a person's view or viewpoint. We also investigated modifiers of view and multiple and list the top twenty in Table 4. From this information, we see that authors write frequently about different view types, such as 3D view, map view or timeline view.

The word multiple means numerous, of great number, several or many. In fact the prefix multi-comes from Latin multus meaning much or many. There are many words that are prefixed by multithat might be expected to be used in visualisation, including: multicoloured, multicomponent, multifaceted, multiform and multi-use. However multicoloured and multicomponent do not exist in v6Y (in neither British or American spelling). A list of the top 60 words prefixed by multi- are shown in Table 5 . Another prefix that has a similar meaning to multi but is of Greek origin is poly-. Words such as polymorphic, polymerisation, polygons, polysemy, polynomials are all suitable, but only 21 words that start with poly are found in the whole v6Y corpus. Polygon, polylines and polynomial are the top most occurring words in this category. The most suitable word for our study, in this list, is polyline. While the word polyline is widely used, it is only used in the context of Parallel Coordinate Plots (appearing 18 times per million). Finally, the suffix -fold means "of many parts" (source MED), therefore words ending in fold are potentially of interest to our study. Yet in v6Y the only fold words are manifold, twofold, threefold and unfold, but unfortunately these do not have any word collocations with views, display
Table 4: Frequency of occurrence, showing raw and normalised per million values for the first twenty examples of nouns and verbs modified by multiple and modifiers of view. In the $v 6 Y$ corpus (IEEE VIS TVCG journals 2012-2017).

\begin{tabular}{lrr|lrr} 
multiple (adj.) & $f_{\text {raw }}$ & $f_{\text {pm }}$ & view (n.) & $f_{\text {raw }}$ & $f_{\text {pm }}$ \\
\hline multiple views & 268 & 42.51 & multiple views & 268 & 42.51 \\
at multiple levels of & 101 & 16.02 & the 3D view & 181 & 28.71 \\
multiple attributes & 97 & 15.39 & the timeline veiw & 174 & 27.60 \\
small multiple displays & 80 & 12.69 & map view & 174 & 27.60 \\
multiple variables & 69 & 10.95 & the detail view & 172 & 27.29 \\
multiple sources & 68 & 10.79 & the other views & 162 & 25.70 \\
at multiple scales & 64 & 10.15 & list view & 157 & 24.91 \\
multiple dimensions & 61 & 9.68 & matrix view & 157 & 24.91 \\
multiple instances of & 59 & 9.36 & different views & 153 & 24.27 \\
multiple features & 59 & 9.36 & detailed view & 105 & 16.66 \\
multiple users & 58 & 9.20 & graph view & 98 & 15.55 \\
multiple types of & 55 & 8.72 & the network view & 97 & 15.39 \\
multiple times & 55 & 8.72 & in a single view & 95 & 15.07 \\
multiple sets & 52 & 8.25 & the main view & 92 & 14.59 \\
multiple visualisations & 50 & 7.93 & slice view & 86 & 13.64 \\
multiple datasets & 48 & 7.61 & 2D view & 80 & 12.69 \\
and multiple scattering & 44 & 6.98 & the summary view & 80 & 12.69 \\
multiple fields & 44 & 6.98 & feature view & 75 & 11.90 \\
in multiple ways & 42 & 6.66 & street view & 73 & 11.58 \\
from multiple perspectives & 40 & 6.35 & projection view & 72 & 11.42
\end{tabular}

Table 5: Words that are prefixed with multi- in the v6Y corpus (frequency shown per million). In these results $n$-tuples are not included, but are shown in Table 4, e.g., multiple views (without a hyphen) has a frequency of $\left(268_{\text {raw }}, 42.51_{\text {pm }}\right)$. To understand scale, c6Y: $100_{\text {raw }}$ is $12.16_{\text {pm }}$.

\begin{tabular}{lrrlllll}
\multicolumn{1}{c}{} & $f_{\text {raw }}$ & $f_{p m}$ & & $f_{\text {raw }}$ & $f_{\text {pm }}$ & $f_{\text {raw }}$ & $f_{p m}$ \\
\hline multiple & 4972 & 788.7 & multifaceted & 43 & 6.8 multiply & 19 & 3.0 \\
multivariate & 1262 & 200.2 & multi-view & 42 & 6.7 multiplications & 18 & 2.9 \\
multidimensional & 680 & 107.9 & multilevel & 42 & 6.7 multi-threaded & 18 & 2.9 \\
multiples & 362 & 57.4 & multimedia & 40 & 6.4 multiplying & 17 & 2.7 \\
multi-dimensional & 294 & 46.6 & multiplied & 39 & 6.2 multi-valued & 17 & 2.7 \\
multi-scale & 180 & 28.6 & multi-user & 39 & 6.2 multi-way & 17 & 2.7 \\
multi-resolution & 165 & 26.2 & multi-field & 36 & 5.7 multi-stage & 16 & 2.5 \\
multimodal & 162 & 25.7 & multiclass & 35 & 5.6 multinomial & 16 & 2.5 \\
multiscale & 125 & 19.8 & multi-criteria & 33 & 5.2 multi-step & 16 & 2.5 \\
multi-level & 107 & 17.0 & multi-generational & 31 & 4.9 multi-core & 15 & 2.4 \\
multifield & 94 & 14.9 & multiple-view & 30 & 4.8 multi-pass & 15 & 2.4 \\
multi-touch & 90 & 14.3 & multi-modal & 25 & 4.0 multi-objective & 14 & 2.2 \\
multi-attribute & 88 & 14.0 & multi-focus & 24 & 3.8 multiform & 14 & 2.2 \\
multi-class & 67 & 10.6 & multi-faceted & 24 & 3.8 multi-layer & 14 & 2.2 \\
multiplicity & 60 & 9.5 & multi-chart & 22 & 3.5 multiobjective & 13 & 2.1 \\
multiresolution & 57 & 9.0 & multitouch & 21 & 3.3 multicriteria & 12 & 1.9 \\
multilinear & 53 & 8.4 & multi-pipeline & 20 & 3.2 multi-volume & 12 & 1.9 \\
multitude & 52 & 8.3 & multiple-choice & 20 & 3.2 multi-channel & 12 & 1.9 \\
multi-variate & 46 & 7.3 & multi & 20 & 3.2 multi-fields & 12 & 1.9 \\
multiplication & 43 & 6.8 & multi-relational & 19 & 3.0 multisource & 11 & 1.7
\end{tabular}

or visualisations, because they are only used to describe theories, models and the structure of the paper.

\subsection{What words have authors used instead of "view"?}

Words occurring in similar contexts tend to be related in meaning. Therefore, to explore what words have been used instead of view we automatically create a thesaurus of words from the v6Y corpus in SketchEngine. Each thesaurus was produced by comput- 

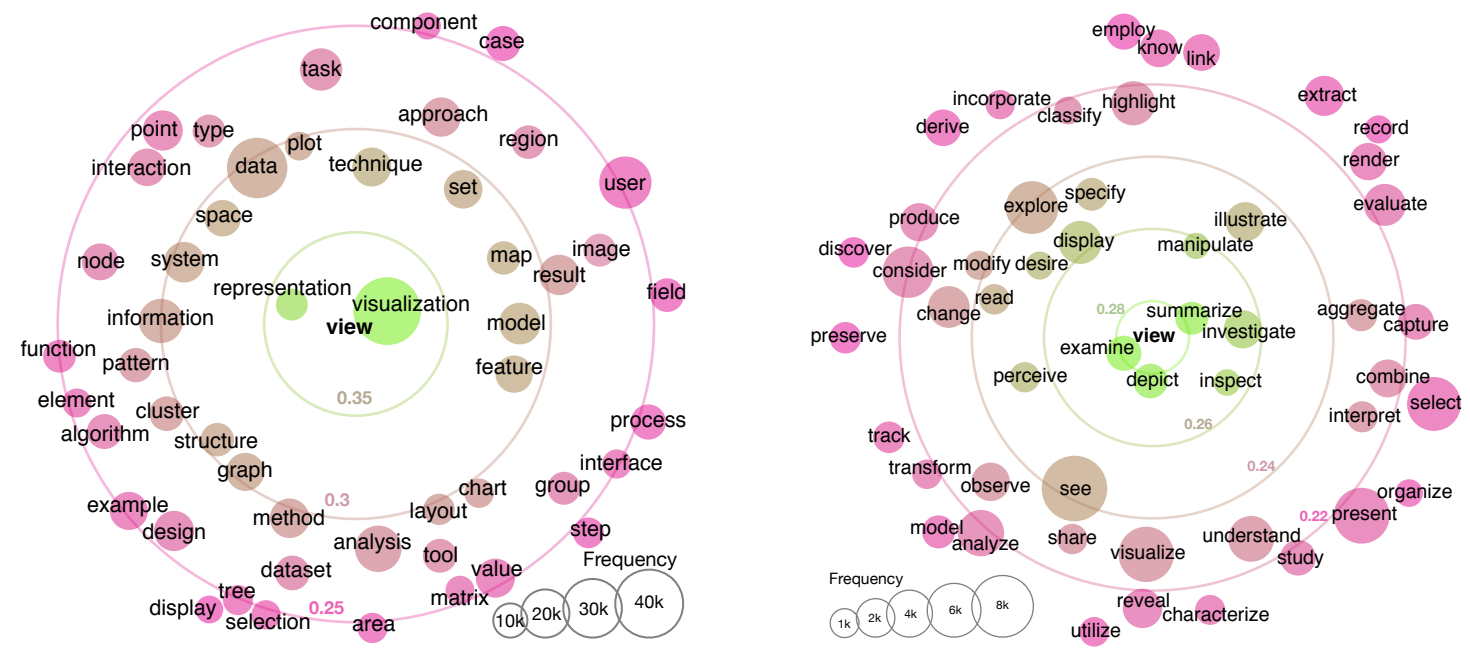

Figure 1: Two figures showing the top fifty thesaurus words for the lemma view. Left depicts view as a noun. Right shows view as a verb. The position is determined by the LogDice score (closer to the centre is a larger score; circle size depicts frequency.

ing the similarity score between two words $w_{1}, w_{2}$, to find all overlaps where $w_{1}$ and $w_{2}$ share a collocation, and share a similar meaning, and ordered by their frequency using the LogDice similarity score $\left[\mathrm{KBB}^{*} 14\right]$. $\operatorname{LogDice}=14+\log _{2} \frac{2 f_{x y}}{f_{x}+f_{y}}$, where $f_{x}$ is the number of occurrences of word $\mathrm{X}$, and $f_{x y}$ is number of co-occurrences of words $\mathrm{X}$ and Y. Figure 1 shows two circle plots from our generated thesaurus, with the lemma view as a noun (left) and as a verb (right). Words such as visualisation, representation, technique, chart, plot and structure can all be used instead of view. We note that there are challenges to automatically generating a thesaurus, as some words have different meanings yet are used in similar patterns, leading to some false positives within the result. But even with these limitations, intuitively these results seem sensible, and they represent a list of possible alternatives for the word "view".

In our created thesaurus we observe a widespread use of words that have general meaning, such as charts, plots, graphs, diagrams, images or pictures. One result is that authors often refer to the visualisation picture indirectly; rather than referring to a particular figure or scatterplot, they write about the algorithm, its interaction, or they refer to a specific point on the graph, or else discuss the layout or their results. More importantly, though, we observe many specific (named) visualisation types being used. From our analysis, we discover that the most common visualisation type that is used in $\mathrm{v6Y}$ is scatterplot $\left(2318_{\text {raw }}, 281.9 \mathrm{pm}\right)$, followed by histogram $\left(1720_{\text {raw }}, 209.1_{\text {pm }}\right)$, timeline $\left(1073_{\text {raw }}, 130.5_{\text {pm }}\right)$ and bar chart $\left(892_{\text {raw }}, 108.5 \mathrm{pm}\right)$. Interestingly authors are over thirteen times more likely to write bar chart than barchart $\left(66_{\text {raw }}, 8.0_{\mathrm{pm}}\right)$, yet prefer boxplot $\left(321_{\text {raw }}, 39.0_{\mathrm{pm}}\right)$ over box plot $\left(43_{\mathrm{raw}}, 5.2_{\mathrm{pm}}\right)$. Some of the named visualisations are composite types, such as grid, matrix and trellis plot. For example, small multiples $\left(323_{\text {raw }}, 51.2_{\mathrm{pm}}\right)$, matrix view $\left(159_{\text {raw }}, 19.1_{\mathrm{pm}}\right)$, scatterplot matrix $\left(120_{\text {raw }}, 14.6_{\mathrm{pm}}\right)$ and matrix visualisation $\left(92_{\text {raw }}, 11.2_{\mathrm{pm}}\right)$. Authors often name their new visualisation designs and reference them throughout their own paper. However, unless their technique becomes popular and is used by many people (like that of treemaps [SW01]), the frequency of these new less-familiar designs will be low. It is be- yond the scope of this paper to do a full review of all visualisation types, and other researchers have investigated and classified different types, including Bertin's categorisation of Diagrams, Networks, Maps, Charts/Graphs, Tables/Matrix, Symbols [Ber81]; Lohse et al. [LRBW90] categorisation of visualisation types and Lengler and Eppler's [LE07] periodic table of visualisation techniques.

\section{Breadth of terms for "multiple-view" (goal 3)}

We investigate the breadth of terms that have the same sense as "multiple views". To create our full word list (Table 6) - as introduced in Section 3 - we started with terms in Roberts [Rob07], Weaver [Wea04] and Gleicher [GAW*11], and added further words, from the OED and MED dictionaries, and further terms through the generation of a bespoke thesaurus from the v6Y corpus (building each thesaurus as explained in Section 6.2). As we go through the breadth of terms, we refer to the word list in Table 6 (which is arranged alphabetically, and structured with the word sense $a$ to $e$, to allow readers to easily find a particular word or phrase), we highlight them in bold throughout the following sections, and give examples and frequencies in Table 7.

\subsection{Terms for multiple perspectives (sense a, Manner)}

Every problem can be tackled from a different perspective, and designing solutions in the visualisation domain is no different [RHR17, RHR16]. For example, when creating a dashboard visualisation for a library information system, we could think of building the system for the main librarian who has to manage staff and assets; they have a building containing librarians and administrators, books, data and resources, etc. Or we could consider building the tool from the standpoint of the borrower; they have an identifier, can request a publication, borrow and return a publication, and see visual depictions of their borrowing habits and deadlines for loans, etc. These views are contexts, and can be used to create programs that are equally suitable yet have different purposes and are developed for different users [Rei85].

Thus a view is a "set of modules that represent one aspect of an 
Table 6: List of different senses (a to e) for multiple-views, ordered alphabetically; refer to Table 7 for quantitative data and examples.

\begin{tabular}{|c|c|c|c|}
\hline Manner (a.) & Data (b.) & Picture (c.) & \\
\hline alternative & fan-out & $\begin{array}{l}\text { Juxtaposed } \\
\text { aligned }\end{array}$ & $\begin{array}{l}\text { Grid } \\
\text { dashboard }\end{array}$ \\
\hline brainstorm & lattice & alternative & grid \\
\hline concerns (separation of) & model & bracketed & lattice \\
\hline designs & multidimensional & comparison views & matrix \\
\hline frame & multifaceted & difference views & panel plot/chart \\
\hline multiple intelligence & multimodal & display & reorderable matrix \\
\hline parallel & multirun & dual views & scatterplot matrix \\
\hline perspectives & multivariate & focus + context & small multiples \\
\hline plan & spatiotemporal & form & splom \\
\hline sketch & & juxtaposition & spreadsheet \\
\hline think & & multiform & tabular \\
\hline thinking (creative) & & multiview & trellis \\
\hline thinking (design) & & non-aligned & \\
\hline thinking (lateral) & & parallel & \\
\hline thinking (visual) & & representation & \\
\hline viewpoint & & side-by-side & \\
\hline
\end{tabular}

$\begin{array}{llll}\begin{array}{l}\text { Superimposed } \\ \text { distortion }\end{array} & \begin{array}{l}\text { Coordinated } \\ \text { brushing }\end{array} & \text { Projection (d.) } & \text { Opinion (e.) } \\ \begin{array}{l}\text { head-up display } \\ \text { overlay }\end{array} & \begin{array}{l}\text { dependent } \\ \text { coordinated }\end{array} & \text { frame } & \text { misrepresentation } \\ \text { popup } & \text { dependent } & \text { level of detail } & \text { primartiperspectivity } \\ \text { superimposed } & \text { focus+linking } & \text { projection } & \text { multiple narratives } \\ \text { view on a bat } & \text { linked highlighting } & \text { semantic detail/zoom } & \text { multistable } \\ \text { worlds in miniature } & \text { linked views } & \text { stereo viewing } & \text { opinion } \\ & \text { master/replica } & \text { view, plan, aerial, side } & \text { polyperspectivity } \\ & \text { master/slave } & \text { viewpoint } & \text { polysemic } \\ & \text { painting } & \text { viewport } & \text { storytelling } \\ & \text { primary/secondary } & \text { zoom } & \text { uncertainty } \\ & \text { synchronised views } & & \end{array}$

entire system" [MEH01]. Consequently, a developer can consider many viewpoints of a system. The ISO/IEC/IEEE 42010 Systems and software engineering (architecture description) [MEH01] explains that a system is situated in an environment, stakeholders have interest in the system, and the system has a purpose that is defined by a set of concerns [NKF94]. Depending on the project, there may be many stakeholders, such as clients, developers, suppliers, maintainers etc. And there will be several concerns that the developer will need to address, such as data privacy, data integrity, usability, correctness, system integration, limitations of the code, functionality, affordability and time to deliver, etc.

This is exactly what a visualisation developer needs to address: they need to consider various stakeholder concerns (developing a separation of concerns). To approach and develop a suitable visualisation solution, they need to understand where and how the tool will be used (its environment), and make different decisions of how the tool operates, how it is going to be used and deployed, how it will work, etc. So, for example, let us consider developing a visualisation of some crime data. We could imagine creating an App that would visualise data on a mobile phone, and give results to the user based on their location. Or we could imagine a dashboard solution that would visualise crime data on a big screen in a policing operations room. Both solutions are equally valid, and may use the same data, yet each present a different view and specification on a similar challenge. At this high-level conceptual view, the developer cannot implement all solutions. The developer needs to refine the problem to a set of specific requirements and then define these requirements. In other words, they need to frame the problem. The frame is a set of requirements that are made specific to a particular context and environment, and are built to address a particular goal. This idea of frames is used in both requirements determination [Dav02,RHR17] and sensemaking [KMH06]. (Note that the word frame also means frame rate, or a view and is thus also included in the Projection category, d).

There are several pragmatic models $\left[\mathrm{HKN}^{*} 07\right]$ in computing architecture that could help a visualisation designer, such as considering Business, Architecture, Process and Organisation views (BAPO); or considering logical, implementation, process and deployment standpoints. When developing a visualisation solution, rather than thinking about every possible category and solution (a bottom-up approach), developers could use pre-defined structures

to help them find the right solution, methods such as design patterns for information visualisation [HA06], or Munzner's [Mun09] nested model could be used as a guide to help think about the problem. Another design model is the Five Design-Sheet (FdS) method [RHR17, RHR16], where users use different parts of the sheet to prompt them to consider their problem from different viewpoints, to create different design ideas, recorded as alternative sketches. For example, on the second sheet users consider meta information about the project, sketch what their tool could look like, consider interaction, what makes the solution unique, and finally reflect on pros and cons. Similar ideas exist in other domains. For instance teachers can help students to learn through multiple representations [Ain06, Ter97]; because learners may understand a concept better when it is presented in many different ways. In the business world, concepts of creative, design, lateral or visual thinking techniques are used to brainstorm different ideas, and help users consider alternative viewpoints. For instance, de Bono's six thinking hats is a good example that encourages groups of people to think about a problem [DB09] from different perspectives.

To investigate the coverage of these ideas in the visualisation community, we used the v6Y corpus and searched for words within a 5-token (collocation) window. While words such as viewpoints and environment do have specific meanings in this context, they are too general and therefore produce too many false positives in our corpus searches to be useful. Consequently, we focus on the larger phrases. E.g., frame occurs frequently $\left(1730_{\text {raw }}, 210.37_{p m}\right)$, as it includes terms such as frame rate and rendering frames, whereas framing a problem occurs infrequently $\left(63_{\mathrm{raw}}, 7.66_{\mathrm{pm}}\right)$, and separation of concerns is also low in number $\left(4 \mathrm{raw}, 0.49_{\mathrm{pm}}\right)$, whereas design alternatives occurs more often $\left(184_{\text {raw }}, 22.37 \mathrm{pm}\right)$.

\subsection{Terms for multiple data views (sense $b$, Data)}

When a query is made to a database, a new data view is returned. In addition, the visualisation tool can itself process, aggregate, filter, bin and classify the data afterwards. By altering different parameters, the user is able to explore the data. Each time the user changes the data (either from a database query or interactive filter) there is a choice to replace (and clobber) the current data view, or make a new view. The latter operation is a fan-out process of a dataflow model, where (e.g.) a different filtering on the data will create a new view [Rob98a]. Fan-out is often used when researchers wish 
to compare two or more queries side-by-side. Consequently, there are many terms about generating and exploring data, such as investigating multifaceted data $\left(18_{\text {raw }}, 2.19_{\mathrm{pm}}\right)$, exploring different dimensions from multidimensional data $\left(23_{\text {raw }}, 2.80_{p m}\right)$, comparing and investigating multirun data $\left(2_{\text {raw }}, 0.24_{p m}\right)$, focusing on different perspectives of multivariate data $\left(37_{\mathrm{raw}}, 4.5_{\mathrm{pm}}\right)$ or investigating spatio-temporal data, to storing data in a neighbourhood lattice structure $\left(88_{\text {raw }}, 10.70_{\mathrm{pm}}\right)$.

\subsection{Terms for multiple visualisations (sense c, Picture)}

We looked through many seminal works, including [Rob00b, Rob98a, GAW*11, NS00, WBWK00, BRR03, Ber81, Tuf90, AA03] noting keywords. Again we used affinity diagramming to help categorise the ideas. We group the names into terms that express (i) view juxtaposition, (ii) grid and tabular layouts, (iii) superposition, and (iv) coordination.

(i) Juxtaposition. The general idea to put two views close together is a simple yet effective design strategy, and consequently there are many words that have the same sense, including sideby-side, dual views [PW03], and parallel views (see Table 7 for a summary of terms, frequencies and examples from the v6Y corpus). There are many examples that use this technique, including Henry and Fekete [HdF06] and Namata et al. [NSGS07], who demonstrate tools that display side-by-side network graphs. The term parallel is sometimes used to explain several side-byside views, or bracketed views "where a principal view is supported with two [or more] additional views from slightly different parametrisations" [Rob04]. However, the word parallel is rarely used in this context (only 4 times in v6Y) and most occurrences are used to describe Parallel Coordinate Plots (PCPs), and bracketed does not exist in collocation with the word view, but used to reference grammar structures or reference items in (e.g.) a figure.

The term alternative representations is used quite frequently in visualisation texts. In the c6Y corpus, there are 1487 instances $\left(180.82_{\mathrm{pm}}\right)$ of alternative representations, alternative views or alternative designs. Words alternative and alternate could be used interchangeably in American English, yet alternate usually means "every other, or every second". Thus we encourage the use of alternative, especially in this context, and to mean "another way of displaying the same data". In addition, the use of alternative views is convenient to reference haptic, tangible or other different forms, even if they display data using a different human sense [RRB*14]; such tangible forms enable the user to hold and physically manipulate interactive data sculptures [JD13]. Another general term is multiform, which means different shapes, forms or kinds, and has a Latin origin multiformis meaning many-shaped, manifold. It is usually attributed to visualisations of the same data but with different chart types [Rob98b]. Finally, the word multi-view is a contracted form of multiple-views, and is used less often (see Table 5 and notice the frequencies of multiple view and multi-view).

With juxtaposed views users can compare the results displayed in one view directly with the other $\left[\mathrm{GAW}^{*} 11\right]$. This technique has several names including comparison views or difference view. Often the views are aligned together such that they can be directly compared. This could be achieved with visual lines, or by synchronising the view transformations to keep the same information visually aligned between views. There are many types of data that benefit from these aligned views, e.g., it is useful for aligning temporal data or gene expression data. Keeping multiple views consistent is an important aspect of designing good multiple view systems [QH18]. Because we are considering the idea of comparison, it is possible (and sometimes better) to merge the information into one view. This could be achieved through superposition and overlaying [Rob98a] the information as transparent or semitransparent superposition layers, or could be achieved through new design strategies. Comparison viewing is discussed in great detail by Gleicher et al. [GAW*11, Gle18], explained as an "explicit encoding" and further detail is out of scope in this paper.

(ii) Grid layout. Before thinking about gridded or tabular structures, we need to briefly consider the size and criteria of a view. Up to now, our views have been individual entities that can be understood if they are seen on their own; they are self-contained visualisations. However, now we are starting to consider (what are typically) smaller, yet many more, visualisations that are put together into a grid. If there are lots of windows that are placed near each other, yet each is a self-contained visualisation (e.g., with legends), then we could treat them as parallel or side-by-side views. But when the views become smaller in size, or they are missing axis and other such information, then they are becoming a grid of visualisations. Other names include panel, trellis, lattice, faceted or tiled chart. The grid of visualisations could be displayed in a spreadsheet [CBRK97] (where distortion could be used to show some rows in higher detail). Small multiples are a grid or tabular organisation of visualisations, usually the same type, which share scales, size, are simple to understand, and the layout and positioning of their placement is meaningful $\left[\mathrm{MXH}^{*} 03\right]$. The idea originated in 1870s, when Eadweard Muybridge photographed a "horse in motion" but the technique was popularised by Tufte (c.1990) [Tuf90]. Often, the grid positions of the views are meaningful. They could be alphabetical, or ordered by another parameter value. Another similar idea is that of business dashboards, where statistical and metric data is displayed as a set of simple charts. There are many different meanings of dashboards from "tiled layout of key metrics as simple charts ... [to] a functional tool" [SCB*19]. Another gridded layout, of statistics, is the scatterplot matrix (or splom) [CLNL87]. These plots enable the user to perform pairwise comparison of the data. These gridded charts are also named lattice charts, lattice plots or lattice graphs. The final extension of this idea is to put even more abstract display into each cell of the grid, and make each component even smaller, we could place a glyph or single bar into each cell (which can be reorganised) and thus deliver a reorderable matrix visualization [Ber81,SM05] (a matrix as rows and columns of a table, where the ordering of the rows and columns can be adjusted).

(iii) Superimposed views. Up to this point we have assumed that the views are probably near each other and the application is placed on a 2D screen. However views can be embedded inside (often through distortion) or pop up on demand, appear near the location of their request (such as near a mouse pointer, or near the result), or appear in 3D. In 3D virtual environments, there are more locations to position views, including on the $2 \mathrm{D}$ plane in front of the viewer (as a heads-up-display), on a billboard that always faces the user, on a virtual hand in front of a third person view, or directly on the 3D mouse (or pointer) location. We can imagine a situation where information is displayed on a handheld virtual tablet, or a 
Table 7: Frequency (per million) of terms that have similar senses to multiple views; taken from Table 6, and showing results with $f_{p m}>0$, ordered by list of word senses Manner (a.), Data (b.), Picture (c.), Projection (d.) and Opinion (e.). Example sentences from published papers.

\begin{tabular}{|c|c|c|c|c|}
\hline Term & Sense & $f_{p m}$ & & Example \\
\hline alternative & a. c. (jux.) & 180.82 & & Many alternatives to these two choices exist. \\
\hline brainstorm & a. & 1.34 & I & Our team worked together to brainstorm design ideas and give feedback to one another \\
\hline frame & a. & 210.37 & & refer to a frame as a mental construct that positions our knowledge \\
\hline parallel & a. c. (jux.) & 343.29 & & then be visualized using scatter plots or parallel coordinates \\
\hline perspectives & a. & 111.27 & & quantitative analysis from different perspectives \\
\hline plan & a. & 119.90 & & Second, we plan to improve the scalability of the system \\
\hline sep. of concerns & a. & 0.49 & I & These are, firstly, a separation of concern and expertise between training \\
\hline sketch & a. & 95.22 & & discussed alternative scenarios and sketched solutions based on \\
\hline think & a. & 53.99 & 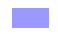 & we added transcribed information from thinking aloud protocols. \\
\hline viewpoint & a. d. & 25.90 & $\square$ & The original viewpoint was chosen as a random side of the object. \\
\hline fan-out & b. & 0.36 & I & as both are represented by fan-outs in the graph \\
\hline lattice & b. c. (grid) & 8.27 & 口 & via small multiples, in the form of trellis, lattice, grid, or panel charts, \\
\hline multidimensional & b. & 155.77 & & A .. framework for unsupervised multidimensional data exploration using low dimensional \\
\hline multifaceted & b. & 9.85 & $\square$ & the expert also wants to take a multifaceted approach requiring several variables \\
\hline multimodal & b. & 27.97 & $\square$ & However, not all multimodal networks have such an existing hierarchical structure \\
\hline multirun & b. & 0.97 & I & visualizing scalar variables in an ensemble or multi-run simulation, \\
\hline multivariate & b. & 189.94 & & to guide the users through the multivariate data exploration process \\
\hline solutions & b. & 122.94 & - & The majority of the proposed solutions have been driven by the requirements of expert \\
\hline spatiotemporal & b. & 90.47 & - & This is true for spatiotemporal selections as well as for selections \\
\hline aligned & c. (jux.) & 14.47 & 口 & summary view and the detail view are aligned at the first event \\
\hline bracket & c. (jux.) & 3.65 & 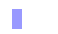 & depict two additional views alongside that bracket the parameterization \\
\hline dashboard & c. (jux.) & 15.08 & $\square$ & Users create data widgets on the dashboard canvas, and widgets can then be freely moved \\
\hline difference & c. (jux.) & 66.64 & $\square$ & features can be assessed using a difference view comparing different calculation results \\
\hline display & c. (jux.) & 732.05 & & we intend to display different semantic levels of abstraction. \\
\hline dual & c. (jux.) & 34.05 & $\square$ & tightly coupled dual view for the discovery of overlap and anomalies \\
\hline focus\&context & c. (jux.) & 40.49 & $\square$ & scalable tree comparison using focus + context with guaranteed visibility \\
\hline form & c. (jux.) & 200.15 & 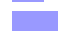 & correlation across multiple valid visual forms can be quantified, compared, and ranked \\
\hline juxtaposition & c. (jux.) & 20.31 & 口 & Data are often compared by juxtaposition using coordinated multiple views with linking \\
\hline multiform & c. (jux.) & 2.55 & I & Exploring high-d spaces with multiform matrices and small multiples \\
\hline multiview & c. (jux.) & 5.72 & 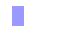 & the log data are used to generate the multi-view visualization \\
\hline non-aligned & c. (jux.) & 0.49 & I & can be either axis-aligned or non-axis-aligned \\
\hline representation & c. (jux.) & 642.43 & & These visual representations support locate and explore search \\
\hline side-by-side & c. (jux.) & 34.17 & $\square$ & need to compare multiple visualizations side-by-side and interactively manipulate them \\
\hline grid & c. (grid) & 257.56 & & We depict each set as an $\mathrm{m} \times \mathrm{n}$ grid of locations \\
\hline matrix & c. (grid) & 463.19 & & These icons are arranged in a matrix style. \\
\hline panel chart/plot & c. (grid) & 1.46 & I & Panel charts still suffer from problems when large magnitude data is used. \\
\hline splom & c. (grid) & 25.90 & $\square$ & can be used to quickly scan a SPLOM to find interesting (or similar) patterns \\
\hline spreadsheet & c. (grid) & 19.46 & 口 & with a stack of two-dimensional spreadsheets showing all possible combinations \\
\hline tabular & c. (grid) & 49.74 & 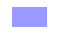 & Such data is commonly stored in a tabular format as spreadsheets \\
\hline trellis & c. (grid) & 3.53 & ! & This algebra can express layered plots, trellis plots, and arbitrary multiple view displays \\
\hline distortion & c. (super) & 62.75 & - & Their technique uses a timeline distortion technique to accommodate \\
\hline head-up display & c. (super) & 0.36 & I & Overlay of symbolic data in a headsup display works in a similar fashion \\
\hline overlay & c. (super) & 89.74 & & Superposition involves overlaying one object over another one \\
\hline popup & c. (super) & 4.99 & - & use a right click menu to open a popup view where relevant documents are listed. \\
\hline worlds in mini. & c. (super) & 0.12 & | & Virtual reality on a WIM: Interactive worlds in miniature \\
\hline brush & c. (coord) & 178.39 & & Using linking \& brushing, users can then explore the relationships \\
\hline coordinated & c. (coord) & 72.72 & L & Illustration of coordinated linked views with brushing support \\
\hline cross-filter & c. (coord) & 8.03 & 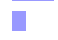 & Using cross-filtering to analyze many-to-many relationships \\
\hline dependent & c. (coord) d. & 61.65 & 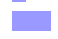 & This is highly likely to be dependent on characteristics of data \\
\hline focus+linking & c. (coord) & 2.43 & 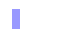 & The navigation bar also displays a slidable focus window, which is linked to the \\
\hline link & c. (coord) & 451.76 & 口 & integrating the two views into a linked view system has proven remarkably effective \\
\hline linked views & c. (coord) & 31.37 & $\square$ & both experts confirmed that the linked views helped them build the connection \\
\hline linked highlighting & c. (coord) & 1.46 & I & selection is propagated as linked highlighting across all views \\
\hline painting & c. (coord) & 20.55 & $\square$ & This widget allows direct painting of the two most meaningful patterns \\
\hline synchronised & c. (coord) & 31.50 & - & multiple views allows for data as well as visual synchronization across them \\
\hline level of detail & d. & 33.68 & - & a visual analytics system to support level-of-detail exploration of event sequence data \\
\hline plan, aerial, side & d. & 9.24 & $\square$ & Here the side view of the rotor is shown. \\
\hline primary views & d. & 12.65 & 口 & The primary network view and the tree view are coupled \\
\hline projection & d. & 355.08 & 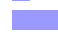 & fast generation of low-dimensional projections that can be evaluated and visualized \\
\hline semantic & d. & 121.85 & & For example, in semantic zooming a visualization might use different \\
\hline stereo & d. & 13.62 & $\square$ & They thought the stereo was cool but offered them no benefits \\
\hline viewport & d. & 16.54 & $\square$ & The user can also interactively change the viewport \\
\hline zoom & d. & 151.40 & 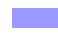 & Users can also zoom in and out on the time axes \\
\hline misrepresentation & e. & 0.61 & I & powerful effects in terms of misrepresentation, disinformation, and even deception \\
\hline narratives & e. & 12.53 & 口 & supports the construction of simple narratives through the exploration of events \\
\hline opinion & e. & 89.86 & 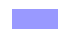 & understanding of key concepts and opinions in a large social media text collection \\
\hline storytelling & e. & 25.54 & $\square$ & systems have been incorporating storytelling into their design \\
\hline uncertainty & e. & 491.52 & - & positions on the left, and the uncertainties in the positions on the right \\
\hline
\end{tabular}


bat or a paddle that is being held by the user in the 3D world. The user can raise their hand to view the information, hence the phrase view on a bat [Rob07]. Augmented reality and visualizations is another growth area [BSB $\left.{ }^{*} 18\right]$, and in fact many researchers are working towards moving visualisation away from the desktop environment [RRB* 14]. These concepts are infrequently discussed in visualisation texts (see Table 7).

(iv) Coordination and linking of views. The idea of linking, coordinating or synchronising interaction across views is a popular technique within visualisation; it has been well studied and there are many well-cited papers, including a state of art review [Rob07], rudiments of coordination [BRR03] and others including [NS00, Wea04, Wea08, Wea10, Rob05]. Usually a user would select a set of items (e.g., by enclosing through a lasso selection or hovering over some elements) which are then shown to the user by a change in colour (highlight) or some other operation (such as a change in size). When this operation occurs dynamically the views are being brushed. Brushing is a set of techniques to perform interactive highlighting between views [War94]; also known as painting multiple views [BMMS91]. More complex coordinations are possible, including linked navigation, cross-filtered views (where the filter operation of one view is based on the values that are selected in another view).

There are also several (more general) coordinated multiple view concepts that are appropriate for us to include. For instance, while both the phrase parallel and dual imply that all views are equally important, the designer may wish to have one view as the primary and the other as a secondary view. This relationship has been called master/slave [Rob07]. However, this phrase is not used in this form in v6Y, and in fact it would be better expressed by an alternative phrase such as master-replica or primary-secondary or dependent views. The idea of dependent views however is broader than displaying two views side-by-side, because the view could be dependent on something else other than a view. For example, we could imagine a situation when the information visualisation in one window could be dependent on the position of a virtual user standing on a virtual map in a 3D world; when they move their avatar, the display gets updated. Consequently, for more detail about these techniques see Boukhelifa et al. [BRR03] on the rudiments of coordination. With these linked visualisations, one view could act as the focus and the other provides context, hence the term focus+context, where one view is shown in greater detail (focus) and the other preserves a global view at reduced detail (context). However, there is no agreed way to write this term [IIS*17], with many variants in v6Y, including focus+context $\left(260_{\text {raw }}, 31.22_{\mathrm{pm}}\right)$, focus-and-context $\left(37_{\mathrm{raw}}, 4.50_{\mathrm{pm}}\right)$, focus and context $\left(31_{\text {raw }}, 3.77_{p m}\right)$, focus\&context $\left(4_{\text {raw }}, 0.49_{p m}\right)$, and less frequent versions with a "+", or "l" and other phrases such as overview and detail $\left(33_{\text {raw }}, 4.01_{\mathrm{pm}}\right)$ having similar meaning.

\subsection{Terms for multiple viewpoints (sense d, Projection)}

Understanding 3D objects depends upon the place where the person is looking. For instance, look to the front of a wheel and it appears rectangular, look to the side and the viewer sees a hole through it. Consequently, although several observers may look at the same object, they may make different conclusions. To overcome this viewdependent challenge, users have to either manipulate the 3D objects in their mind - which may be a struggle for some users [DM97] - or they transform and change the rendered viewport. There are many places in computer graphics where two viewpoints are simultaneously required, such as for stereoscopic imaging [CNSD93], or techniques to render on a volumetric display device [JMY*07]. In computer aided design (CAD), users present three orthogonal viewpoints known as multiview projections. Much like the concept of master/slave or dependent viewing, often in a set of plans there is one view, the primary view, that contains most information and is the main representative diagram of the data. One current trend in visualisation is to investigate how a visualisation can be placed in virtual worlds, or augmented into the real-world [RRB*14]. Developers are placing scatterplots, barcharts and other visualisations within $3 \mathrm{D}$ worlds $\left[\mathrm{BDC}^{*} 16\right]$. So it will be interesting to research how view dependence in 3D affects the perception of 3D immersive visualisations. Another way to change the viewpoint is to zoom into or away from the 3D object. Zooming can be linked to a semantic change, to provide Level of Detail (LOD) change. Physical zooming is also possible, which is particularly useful for visualisation on large displays [BNB07].

So far we have been considering changing the viewpoint, but we can think about this challenge in reverse, and ask the question: where was the viewer standing to take this picture? There are many computer techniques, such as structure from motion, that recreate 3D models from a series of 2D pictures taken from multiple viewpoints [MA83, $\left.\mathrm{WBG}^{*} 12\right]$. When investigating v6Y for the terms associated with meaning $\mathrm{d}$, we discover that general terms such as viewport $\left(136_{\text {raw }}, 16.54_{\mathrm{pm}}\right)$, zoom $\left(1245_{\mathrm{raw}}, 151.4_{\mathrm{pm}}\right)$, semantic zoom $\left(1002_{\text {raw }}, 121.85_{\mathrm{pm}}\right)$ are frequently used. In particular the word dependent $\left(507_{\text {raw }}, 61.65_{\mathrm{pm}}\right)$ when it means that something is dependent on some data is far more frequent than meaning a specific graphic projection, such as a view dependent (isosurface) extraction. Likewise, other specific viewpoint types are not often used by the visualisation authors: primary view $\left(104_{\text {raw }}, 12.65_{\mathrm{pm}}\right)$, orthogonal view $\left(16_{\text {raw }}, 1.96_{\text {pm }}\right)$ or physical zoom $\left(4_{\text {raw }}, 0.49_{p m}\right)$. This is surprising, and we assumed they would be more frequently used, especially within the scientific visualisation community.

\subsection{Terms for several interpretations (sense e, Opinion)}

Visualisations are designed for human consumption. The visualisation is not the end-goal, rather they are created to allow the user to understand data. Consequently, individual users may conclude different findings. Perhaps because they misunderstood the view method or layout, maybe the developer misrepresented the information, perhaps some information is erroneous (such as the title, legend, axis or scaling), or maybe the data itself is erroneous. Possibly, the data mapping is ambiguous or uses a confusing colourmap, or the user is colour blind, or the display is inaccurate, with overplotted (overdrawn) points. This is where uncertainty visualisation $\left[\mathrm{BHJ}^{*} 14\right]$ can help, by depicting meta information about the data, or placing error-bars on the views. Unfortunately, sometimes the visual depiction appears perceptually unstable, and therefore is confusing to the observer. This instability may be caused by the arrangement of the visual marks tricking the observer, resulting in a multistable perception [LL99] (the idea that a visual pattern can be seen in different ways, such as the Necker cube, or 
Rubin's vase illusions). Multistability is explored in various texts (such as [RHR17]), and while perception is studied and mentioned in the v6Y corpus $\left(1696_{\text {raw }}, 206.2_{\mathrm{pm}}\right)$ the idea of multistability is not in the v6Y corpus, and it could be an interesting topic to explore in the context of data visualisation.

Finally, we consider narratives and storytelling [RRJH18]. In fact, we have come full circle. At the start of this section, we discussed the idea of multiple views to consider alternative perspectives and alternative designs. In the picture section (meaning c), we created many views to compare or explore the data. Now we focus on telling different stories. The words storytelling and narratives are popular in the visualisation literature. Storytelling is mentioned 210 times in v6Y $(25.54 \mathrm{pm})$. But there are other words that could be used in this context, that are missing from the v6Y corpus. These include multiperspectivity or polyperspectivity, which present multiple perspectives of the same subject to the audience; polysemic/multisemic, which means that a sign or symbol can have many meanings; or multivocality, which means that each meaning is equally likely to occur. The word multivocality is often used to talk about historic events; because of sparse data and evidence many interpretations could be equally valid. It is interesting to note that none of these terms are included in the v6Y corpus. We suggest that this is an area for future work.

\section{Discussion and conclusions}

As the subject of visualisation develops, so specific areas (such as the area of multiple views) are maturing. For example, we have state of the art reviews [Rob07], rudiments [BRR03], design guidelines [WBWK00], and tools all that help designers create multiple view systems. But the breadth of research does not necessarily make it easy for people to fully understand or comprehend the topic; on the contrary, it can confuse authors and can also lead to complacency. In fact, one of our initial stimuli for performing this work, was when we had struggled to explain the different senses of multiple views to our students. This drove us to consider more critically what others were doing. For instance, we started to observe, in some cases, that the term multiple views was being casually used. We wondered whether some people felt pressured to say that their tool supported "multiple views" without really explaining how it was implemented, what it was providing, or what it meant to the user. Particularly, we saw that the phrase coordinated multiple views (CMV) was used, when the phrase linked highlighting would have been more suitable. While linked highlighting and brushing are important aspects of CMV, used as synonyms they oversimplify the topic and ignore prior research. We therefore want to encourage authors to take care over the words they use, clearly express their arguments, find w ords that t ruthfully express their thoughts, and accurately reflect the completed research.

Multiple views is not the only topic where this is an issue, but in this paper we have provided in-depth study of terms in the topic of multiple views: investigating senses, term frequency and breadth of words in several corpora including a 6 million word corpus of IEEE VIS TVCG papers between 2012 and 2017. We believe that our elucidation of the senses (Section 5) along with the itemisation of words (Table 6) will act as a reference for authors, and could be used by teachers to help explain the topic and the breadth of the ideas. The statistics on word use and real-world examples (in Table 7) provides good examples of how the words can be used in sentences, to help authors write better. Finally, throughout the text we provide meanings for less familiar words, to help readers learn more about the topic, and appreciate its breadth.

In fact, several terms are not widely used by the community (ie., they have lower frequency counts or do not exist in the v6Y corpus), but do have the potential for being useful for visualisation; these include separation of concerns, multiform, multistable, multivocality and polysemic. Furthermore, we observe that most of these words are either in our first or last category (i.e., in Manner or Opinion). The former includes concepts such as planning, thinking, sketching and outlining the idea (e.g., [RHR16, RHR17]), whereas the latter addresses storytelling, presentation, delivery, interpretation or understanding of the underpinning ideas (e.g. [RRJH18, WBE*06, SH10, BLB*17]). Both categories represent fast-developing areas in visualisation; with researchers investigating new ways to better design a visualisation, and others investigating how best to tell stories about their data. We believe that these words will become more prevalent over time. Certainly, there are opportunities for researchers to investigate and further explore many of these ideas and words, and use them to be creative in their next visualisation design study.

Language is constantly changing. Consequently, we acknowledge limitations to our analysis. We scoped our study on the topic multiple views, and to focus on words published between 201217, with most words coming from the Transactions on Visualisation and Computer Graphics journal. Certainly, other publication venues may have different frequency counts. E.g., the concepts of multivocality would be more popular in heritage and archaeology journals, while storytelling would be more frequently used in a journalism journal. But our analysis has been thorough and detailed, and represents a snapshot of the community's use of multiple views. As the visualisation domain develops, its language will change. For instance, with the rise of immersive and interactive visualisation experiences [RRB*14], the assumption that a view is a $2 \mathrm{D}$ entity may change to be $3 \mathrm{D}$, with users immersed inside their data. Additionally, word use will be affected by the democratisation of visualisation techniques, where the public will create and tell their own visualisation stories. We leave many questions to future work, such as how non-academics explain visualisations, if the vocabulary changes depending on venue, or how the community uses other (non multiple view) words. But in this work we have comprehensively explored senses and collocated words in the topic multiple views, and believe that our findings and taxonomy of the terms can help readers frame their ideas, improve their written work, and that the community will have a better grasp of the expressiveness of ideas surrounding multiple views.

\section{Acknowledgements}

We acknowledge and thank discussions with Chris North, Chris Weaver and John Stasko on multiple views, and discussions with Panagiotis Ritsos. This work is funded by the Arts and Humanities Research Council, UK (AHRC) grant AH/P003508/1, ColloCaid: combining learner needs, lexicographic data and text editors to help learners write more idiomatically. 


\section{References}

[AA03] ANDRIEnKo N., ANDRIEnKo G.: Coordinated views for informed spatial decision making. In Proceedings International Conference on Coordinated and Multiple Views in Exploratory Visualization - CMV 2003 - (July 2003), pp. 44-54. doi:10.1109/CMV.2003. 1215002

[AC08] AbBasi A., Chen H.: Cybergate: A design framework and system for text analysis of computer-mediated communication. MIS Quarterly 32, 4 (2008), 811-837. doi : 10 .2307/25148873.

[Ain06] AINSwORTH S.: Deft: A conceptual framework for considering learning with multiple representations. Learning and instruction 16, 3 (2006), 183-198. doi:10.1016/j.learninstruc.2006.03. 001.

[Ant13] Anthony L.: A critical look at software tools in corpus linguistics. Linguistic Research 30, 2 (2013), 141-161. doi : 10 . 17250 / khisli.30.2.201308.001.

[BC87] BeCKer R. A., Cleveland W. S.: Brushing Scatterplots. Technometrics 29, 2 (1987), 127-142. doi : $10.2307 / 1269768$.

[BDC*16] BaCH B., Dachselt R., Carpendale S., DWyer T. COLlins C., LEE B.: Immersive analytics: Exploring future interaction and visualization technologies for data analytics. In Proceedings of the 2016 ACM on Interactive Surfaces and Spaces (2016), ACM, pp. 529533. doi:10.1145/2992154.2996365.

[Ber81] BERTIN J.: Graphics and graphic information processing. Walter de Gruyter, 1981.

[BHJ*14] Bonneau G.-P., Hege H.-C., Johnson C. R., Oliveira M. M., Potter K., Rheingans P., Schultz T.: Overview and state-of-the-art of uncertainty visualization. In Scientific Visualization. Springer, 2014, pp. 3-27. doi : 10.1007/978-1-4471-6497-5_

[BLB*17] BRehmer M., LeE B., BACH B., Riche N. H., MunZneR T.: Timelines revisited: A design space and considerations for expressive storytelling. IEEE Transactions on Visualization and Computer Graphics 23, 9 (Sept 2017), 2151-2164. doi:10.1109/TVCG.2016. 2614803

[BMMS91] Buja A., McDonald J. A., Michalak J., Stuetzle W.: Interactive data visualization using focusing and linking. In Proceedings of the 2nd Conference on Visualization '91 (Los Alamitos, CA, USA, 1991), VIS '91, IEEE Computer Society Press, pp. 156-163. doi:10.1109/VISUAL.1991.175794.

[BNB07] Ball R., North C., Bowman D. A.: Move to improve: Promoting physical navigation to increase user performance with large displays. In Proceedings of the SIGCHI Conference on Human Factors in Computing Systems (New York, NY, USA, 2007), CHI '07, ACM, pp. 191-200. doi:10.1145/1240624.1240656.

[BP02] BOWKER L., PEARSON J.: Working with specialized language: a practical guide to using corpora. Routledge, 2002.

[BRR03] Boukhelifa N., Roberts J. C., Rodgers P. J.: A coordination model for exploratory multiview visualization. In Proceedings International Conference on Coordinated and Multiple Views in Exploratory Visualization - CMV 2003 (July 2003), pp. 76-85. doi: $10.1109 / \mathrm{CMV} .2003 .1215005$.

[BSB*18] BACH B., SiCAT R., Beyer J., Cordeil M., PFister H.: The hologram in my hand: How effective is interactive exploration of $3 \mathrm{~d}$ visualizations in immersive tangible augmented reality? IEEE Transactions on Visualization and Computer Graphics 24, 1 (Jan 2018), 457467. doi:10.1109/TVCG.2017.2745941.

[CBRK97] Chi E.-H., BARRY P., Riedl J., Konstan J.: A spreadsheet approach to information visualization. In Symposium on Information Visualization (1997), IEEE, pp. 17-24. doi : 10.1109 / INFVIS . 1997.636761.

[Che04] CHEN H.: Compound brushing explained. Information Visualization 3, 2 (2004), 96-108. doi:10.1057/palgrave.ivs. 9500068
[CLD11a] Culy C., LYDING V., DitTMAnN H.: XLDD: Extended linguistic dependency diagrams. In International Conference on Information Visualisation (IV) (2011), IEEE, pp. 164-169. doi:10.1109/ IV. 2011.42

[CLD11b] Culy C., Lydingand V., DitTMann H.: Structured parallel coordinates: a visualization for analyzing structured language data. In Proceedings of the 3rd International Conference on Corpus Linguistics, CILC-11 (2011). doi:10.1.1.225.3671.

[CLNL87] CARR D. B., LitTlefield R. J., NiChOlson W. L., LiTTLEFIELD J. S.: Scatterplot matrix techniques for large N. Journal of the American Statistical Association 82, 398 (1987), 424-436. doi:10.1080/01621459.1987.10478445.

[CNSD93] CruZ-Neira C., SAndin D. J., DeFanti T. A.: Surroundscreen projection-based virtual reality: The design and implementation of the cave. In Proceedings of the 20th Annual Conference on Computer Graphics and Interactive Techniques (New York, NY, USA, 1993), SIGGRAPH, ACM, pp. 135-142. doi:10.1145/166117.166134.

[Dav02] Davidson E. J.: Technology frames and framing: A sociocognitive investigation of requirements determination. MIS Quarterly 26, 4 (2002), 329-358. doi: 10 . 2307/4132312.

[DB09] De Bono E.: Six Thinking Hats. Penguin UK, 2009.

[DM97] Diwadkar V. A., MCNAmara T. P.: Viewpoint dependence in scene recognition. Psychological Science 8, 4 (1997), 302-307. doi : $10.1111 / j .1467-9280.1997 . t b 00442$.x.

[FDC*18] Fu S., DONG H., CUI W., ZHAO J., QU H.: How do ancestral traits shape family trees over generations? IEEE Transactions on Visualization and Computer Graphics 24, 1 (Jan 2018), 205-214. doi:10.1109/TVCG.2017.2744080.

[FFT74] Fisherkeller M., Friedman J., Tukey J.: Prim-9: An interactive multi-dimensional data display and analysis system. In Scientific Computer Information Exchange Meeting, May 2-3 (1974), pp. 111120

[FG18] FRANKENBERG-GARCIA A.: Investigating the collocations available to EAP writers. Journal of English for Academic Purposes 35 (2018), 93 - 104. doi : 10.1016 / j. jeap. 2018.07 .003$.

[FGLR*] Frankenberg-Garcia A., Lew R., Roberts J. C., ReES G. P., SHARMA N.: Developing a writing assistant to help eap writers with collocations in real time. ReCALL 31,1,23-39. doi:10.1017/ S0958344018000150.

[GAW*11] Gleicher M., Albers D., WAlKer R., Jusufi I., HANSEN C. D., Roberts J. C.: Visual comparison for information visualization. Information Visualization 10, 4 (2011), 289-309. doi:10.1177/1473871611416549.

[GK08] Graham M., Kennedy J.: Multiform views of multiple trees. In 12th International Conference Information Visualisation (IV) (July 2008), pp. 252-257. doi:10.1109/IV.2008.21.

[Gle18] GLEICHER M.: Considerations for visualizing comparison. IEEE Transactions on Visualization and Computer Graphics 24, 1 (Jan 2018), 413-423. doi:10.1109/TVCG.2017.2744199.

[HA06] HeER J., Agrawala M.: Software design patterns for information visualization. IEEE Transactions on Visualization and Computer Graphics 12, 5 (Sept. 2006), 853-860. doi:10.1109/TVCG. 2006. 178

[Har94] HaRTLEY R. I.: Self-calibration from multiple views with a rotating camera. In European Conference on Computer Vision (1994), Springer, pp. 471-478. doi : 10.1007/3-540-57956-7_52.

[Har12] HARDIE A.: CQPweb - combining power, flexibility and usability in a corpus analysis tool. International Journal of Corpus Linguistics 17, 3 (2012), 380-409. doi:10.1075/i jcl.17.3.04har.

[HdF06] HENRY N., D. FEKETE J.: Matrixexplorer: a dualrepresentation system to explore social networks. IEEE Transactions on Visualization and Computer Graphics 12, 5 (Sept 2006), 677-684. doi:10.1109/TVCG.2006.160. 
[HH11] HORNBæK K., HeRTZUM M.: The notion of overview in information visualization. International Journal of Human-Computer Studies 69, 7-8 (2011), 509-525. doi:10.1016/j.ijhes.2011.02. 007

[HKN*07] Hofmeister C., KRUChten P., Nord R. L., Obbink H., RAN A., AMERICA P.: A general model of software architecture design derived from five industrial approaches. Journal of Systems and Software 80, 1 (2007), 106 - 126. doi:10.1016/j.jss.2006.05.024.

[HLD02] Hauser H., Ledermann F., Doleisch H.: Angular brushing of extended parallel coordinates. In IEEE Symposium on Information Visualization, 2002. INFOVIS 2002. (Oct 2002), pp. 127-130. doi:10.1109/INFVIS.2002.1173157.

[HM90] Haber R. B., MCNABB D. A.: Visualization idioms : A conceptual model visualization for scientific systems. In Visualization in scientific computing, G.M.Nielson, B.Shriver, L.J.Rosenblum, (Eds.). IEEE Computer Society, WA, USA, 1990, pp. 75-93.

[Hop98] Hoppe H.: Smooth view-dependent level-of-detail control and its application to terrain rendering. In Proceedings Visualization '98 (Oct 1998), pp. 35-42. doi:10.1109/VISUAL.1998. 745282.

[IHK*17] Isenberg P., Heimerl F., Koch S., Isenberg T., XU P., Stolper C. D., Sedlmair M., Chen J., MÃúller T., Stasko J.: Vispubdata.org: A metadata collection about ieee visualization (vis) publications. IEEE Transactions on Visualization and Computer Graphics 23, 9 (Sept 2017), 2199-2206. doi:10.1109/TVCG.2016. 2615308.

[IIS*17] Isenberg P., Isenberg T., Sedlmair M., Chen J., MÃúlLLeR T.: Visualization as seen through its research paper keywords. IEEE Transactions on Visualization and Computer Graphics 23, 1 (Jan 2017), 771-780. doi:10.1109/TVCG.2016.2598827.

[JD13] JANSEN Y., DRAGICEVIC P.: An interaction model for visualizations beyond the desktop. IEEE Transactions on Visualization and Computer Graphics 19, 12 (Dec 2013), 2396-2405. doi:10.1109/ TVCG.2013.134.

[JMY*07] Jones A., McDowall I., Yamada H., Bolas M., DeBEVEC P.: Rendering for an interactive 360 degree light field display. ACM Transactions on Computer Graphics 26, 3 (July 2007). doi: $10.1145 / 1276377.1276427$.

[JZ16] JIANG X., ZHANG J.: A text visualization method for crossdomain research topic mining. Journal of Visualization 19, 3 (2016), 561-576. doi:10.1007/s12650-015-0323-9.

[KBB*14] KilgarRifF A., Baisa V., BuŠTA J., JAKubÍČEK M., Kovvár̆ V., Michelfeit J., RYChlÝ P., Suchomel V.: The sketch engine: ten years on. Lexicography (2014), 7-36. doi:10.1007/ s40607-014-0009-9.

[KK17] Kunilovskaya M., Koviazina M.: Sketch Engine: A toolbox for linguistic discovery. Journal of Linguistics 68, 3 (2017), 503507. doi:10.2478/jazcas-2018-0006.

[KMH06] Klein G., Moon B., Hoffman R. R.: Making sense of sensemaking 2: A macrocognitive model. IEEE Intelligent Systems 21, 5 (Sept 2006), 88-92. doi:10.1109/MIS . 2006.100.

[KPRP07] Klein G., Phillips J. K., Rall E. L., Peluso D. A.: A data-frame theory of sensemaking. In Expertise out of context: Proceedings of the sixth international conference on naturalistic decision making (2007), New York, NY, USA: Lawrence Erlbaum, pp. 113-155.

[KPV*18] Koytek P., Perin C., Vermeulen J., André E., CARPENDALE S.: Mybrush: Brushing and linking with personal agency. IEEE Transactions on Visualization and Computer Graphics 24, 1 (Jan 2018), 605-615. doi:10.1109/TVCG.2017.2743859.

[Kri87] KRISHNAMURTHY R.: The process of compilation. In Looking up: An account of the COBUILD project in Lexical computing, Sinclair J. M., (Ed.). William Collins Sons and Co. Ltd. London, England, 1987, pp. 62-85.

[KRW*14] KARL R., Roberts J., WILSON A., MÖLler K., Miles
H. C., Edwards B., Tiddeman B., Labrosse F., TrobeBATEMAN E. L.: Picture this! community-led production of alternative views of the heritage of gwynedd. Journal of Community Archaeology \& Heritage 1, 1 (2014), 23-36. doi : 10 .1179/2051819613Z. 0000000003

[KZC16] KIM M. C., ZHU Y., CHEN C.: How are they different? a quantitative domain comparison of information visualization and data visualization (2000-2014). Scientometrics 107, 1 (2016), 123-165. doi:10.1007/s11192-015-1830-0.

[LE07] LENGLER R., EPPLER M. J.: Towards a periodic table of visualization methods of management. In Proceedings of the IASTED International Conference on Graphics and Visualization in Engineering (Anaheim, CA, USA, 2007), GVE '07, ACTA Press, pp. 83-88.

[LGF*14] LiU Y., Goncalves J., Ferreira D., XiaO B., Hosio S., Kostakos V.: Chi 1994-2013: Mapping two decades of intellectual progress through co-word analysis. In Proceedings of the 32nd Annual ACM Conference on Human Factors in Computing Systems (New York, NY, USA, 2014), CHI '14, ACM, pp. 3553-3562. doi:10.1145/ 2556288.2556969 .

[LL99] LeOPOLD D. A., Logothetis N. K.: Multistable phenomena: changing views in perception. Trends in Cognitive Sciences 3, 7 (1999), 254-264. doi:10.1016/S1364-6613 (99) 01332-7.

[LRBW90] Lohse J., Rueter H., Biolsi K., WAlker N.: Classifying visual knowledge representations: a foundation for visualization research. In Proceedings of the First IEEE Conference on Visualization (1990), IEEE, pp. 131-138. doi:10.1109/VISUAL.1990. 146374.

[MA83] Martin W. N., Aggarwal J. K.: Volumetric descriptions of objects from multiple views. IEEE Transactions on Pattern Analysis and Machine Intelligence PAMI-5, 2 (March 1983), 150-158. doi: 10.1109/TPAMI.1983.4767367.

[MEH01] MAIER M. W., EMERY D., Hilliard R.: Software architecture: Introducing ieee standard 1471. Computer 34, 4 (2001), 107-109. doi:10.1109/2.917550.

[MEV*14] Madhavan K., ElmQvist N., Vorvoreanu M., Chen X., Wong Y., XiAn H., Dong Z., Johri A.: Dia2: Web-based cyberinfrastructure for visual analysis of funding portfolios. IEEE Transactions on Visualization and Computer Graphics 20, 12 (Dec 2014), 18231832. doi:10.1109/TVCG.2014.2346747.

[MSB90] McDonald J. A., Stuetzle W., Buja A.: Painting multiple views of complex objects. In Proceedings of the European Conference on Object-oriented Programming on Object-oriented Programming Systems, Languages, and Applications (New York, NY, USA, 1990), OOPSLA/ECOOP'90, ACM, pp. 245-257. doi : 10.1145/97945. 97975.

[Mun09] MUNZNER T.: A nested model for visualization design and validation. IEEE Transactions on Visualization and Computer Graphics 15, 6 (Nov 2009), 921-928. doi:10.1109/TVCG.2009.111.

[MXH*03] MacEachren A., Xiping D., Hardisty F., Guo D., LENGERICH G.: Exploring high-D spaces with multiform matrices and small multiples. In IEEE Symposium on Information Visualization 2003 (Oct. 2003), pp. 31-38. doi :10.1109/INFVIS. 2003.1249006.

[NKF94] Nuseibeh B., Kramer J., Finkelstein A.: A framework for expressing the relationships between multiple views in requirements specification. IEEE Transactions on Software Engineering 20, 10 (Oct 1994), 760-773. doi:10.1109/32.328995.

[NSO0] NORTH C., ShNEIDERMAN B.: Snap-together visualization: A user interface for coordinating visualizations via relational schemata. In Proceedings of the Working Conference on Advanced Visual Interfaces (New York, NY, USA, 2000), AVI '00, ACM, pp. 128-135. doi : 10 . $1145 / 345513.345282$.

[NSGS07] Namata G. M., Staats B., Getoor L., Shneiderman B.: A dual-view approach to interactive network visualization. In Proceedings of the Sixteenth ACM Conference on Conference on Information and Knowledge Management (New York, NY, USA, 2007), CIKM '07, ACM, pp. 939-942. doi : 10.1145/1321440.1321580. 
[PHG*18] Pezzotti N., Hollt T., Gemert J. V., Lelieveldt B. P. F., Eisemann E., Vilanova A.: Deepeyes: Progressive visual analytics for designing deep neural networks. IEEE Transactions on Visualization and Computer Graphics 24, 1 (Jan 2018), 98-108. doi: $10.1109 /$ TVCG.2017.2744358.

[PW03] PlumLEE M., WARE C.: Integrating multiple 3d views through frame-of-reference interaction. In Proceedings International Conference on Coordinated and Multiple Views in Exploratory Visualization - CMV 2003 - (July 2003), pp. 34-43. doi:10.1109/CMV. 2003. 1215001 .

[QH18] QU Z., Hullman J.: Keeping multiple views consistent: Constraints, validations, and exceptions in visualization authoring. IEEE Transactions on Visualization and Computer Graphics 24, 1 (Jan 2018), 468-477. doi:10.1109/TVCG.2017.2744198.

[Ray08] RAYSON P.: From key words to key semantic domains. International Journal of Corpus Linguistics 13 (2008), 519-549. doi: 10.1075/ijcl.13.4.06ray.

[Rei85] REISS S. P.: PECAN: program development systems that support multiple views. IEEE Transactions on Software Engineering SE-11, 3 (March 1985), 276-285. doi:10.1109/TSE.1985.232211.

[RFGL*18] Roberts J. C., Frankenberg-Garcia A., Lew R., REES G., SHARMA N.: Visualisation approaches for corpus linguistics: Towards visual integration of data-driven learning. In 3rd Workshop on Visualization for the Digital Humanities, at IEEE VIS, Berlin, Germany (October 2018).

[RHR16] Roberts J. C., Headleand C., Ritsos P. D.: Sketching designs using the five design-sheet methodology. IEEE Transactions on Visualization and Computer Graphics 22, 1 (Jan 2016), 419-428. doi : 10.1109/TVCG.2015.2467271.

[RHR17] Roberts J. C., Headleand C. J., Ritsos P. D.: Five Design-Sheets - Creative design and sketching in Computing and Visualization. SpringerNature, 2017. doi:10.1007/ $978-3-319-55627-7$.

[Rob98a] RoBERTS J. C.: On encouraging multiple views for visualization. In Proceedings IEEE Conference on Information Visualization. (Jul 1998), pp. 8-14. doi:10.1109/IV.1998.694193.

[Rob98b] RoBERTS J. C.: Waltz - an exploratory visualization tool for volume data, using multiform abstract displays. In Visual Data Exploration and Analysis V, Proceedings of SPIE (Bellingham, Washington, USA, 1998), Erbacher R. F., Pang A., (Eds.), vol. 3298, pp. 112-122. doi:10.1117/12.309533.

[Rob00a] RoberTs J. C.: Display models: ways to classify visual representations. International Journal of Computer Integrated Design and Construction (CIDAC) 2, 4 (November 2000), 242 - 250.

[Rob00b] RoBerts J. C.: Multiple-View and Multiform Visualization. In Visual Data Exploration and Analysis VII, Proceedings of SPIE (January 2000), Erbacher R., Pang A., Wittenbrink C., Roberts J., (Eds.), vol. 3960, IS\&T and SPIE, pp. 182-196. doi:http://doi.org/ $10.1117 / 12.378894$.

[Rob04] RoBERTs J. C.: Exploratory visualization using bracketing. In Proceedings of the Working Conference on Advanced Visual Interfaces (New York, NY, USA, 2004), AVI '04, ACM, pp. 188-192. doi : 10 . $1145 / 989863.989893$.

[Rob05] RoBERTS J. C.: Exploratory visualization with multiple linked views. In Exploring geovisualization. Elsevier, 2005, pp. 159-180. doi:10.2312/eurova.20141147.

[Rob07] RobERTs J. C.: State of the art: Coordinated multiple views in exploratory visualization. In Fifth International Conference on Coordinated and Multiple Views in Exploratory Visualization (CMV 2007) (July 2007), pp. 61-71. doi:10.1109/CMV.2007.20.

[RRB*14] Roberts J. C., Ritsos P. D., BADAM S. K., BRODBECK D., Kennedy J., ElmQVist N.: Visualization beyond the desktop-the next big thing. IEEE Computer Graphics and Applications 34, 6 (Nov 2014), 26-34. doi:10.1109/MCG.2014.82.
[RRJH18] RoberTs J. C., Ritsos P. D., JACKSON J. R., HEADlEAND C.: The explanatory visualization framework: An active learning framework for teaching creative computing using explanatory visualizations. IEEE Transactions on Visualization and Computer Graphics 24, 1 (Jan 2018), 791-801. doi:10.1109/TVCG.2017.2745878.

[SCB*19] Sarikaya A., Correll M., Bartram L., Tory M., FISHER D.: What do we talk about when we talk about dashboards? IEEE Transactions on Visualization and Computer Graphics 25, 1 (Jan 2019), 682-692. doi:10.1109/TVCG.2018.2864903.

[SG18] Sarikaya A., Gleicher M.: Scatterplots: Tasks, data, and designs. IEEE Transactions on Visualization and Computer Graphics 24 , 1 (Jan 2018), 402-412. doi:10.1109/TVCG.2017.2744184.

[SH10] SEgEL E., HeER J.: Narrative visualization: Telling stories with data. IEEE Transactions on Visualization and Computer Graphics 16, 6 (Nov 2010), 1139-1148. doi:10.1109/TVCG.2010.179.

[SM05] SiIRTOla H., MÄKINEN E.: Constructing and reconstructing the reorderable matrix. Information Visualization 4, 1 (Mar. 2005), 3248. doi:10.1057/palgrave.ivs. 9500086.

[SW01] Shneiderman B., Wattenberg M.: Ordered treemap layouts. In IEEE Symposium on Information Visualization, 2001. INFOVIS 2001. (2001), pp. 73-78. doi:10.1109/INFVIS. 2001.963283.

[Sza18] SzAFIR D. A.: Modeling color difference for visualization design. IEEE Transactions on Visualization and Computer Graphics 24, 1 (Jan 2018), 392-401. doi:10.1109/TVCG.2017.2744359.

[SZY*18] Shen Q., Zeng W., Ye Y., Arisona S. M., Schubiger S., BURKHARD R., QU H.: Streetvizor: Visual exploration of humanscale urban forms based on street views. IEEE Transactions on Visualization and Computer Graphics 24, 1 (Jan 2018), 1004-1013. doi : 10.1109 /TVCG.2017.2744159.

[TB95] TARR M. J., BÜLTHOFF H. H.: Is human object recognition better described by geon structural descriptions or by multiple views? Comment on Biederman and Gerhardstein (1993). Journal of Experimental Psychology: Human Perception and Performance 21 (1995), 1494. doi:10.1037/0096-1523.21.6.1494.

[Ter97] TERGAN S.-O.: Multiple views, contexts, and symbol systems in learning with hypertext/hypermedia: A critical review of research. Educational Technology 37, 4 (1997), 5-18.

[Tuf90] TUFTE E.: Envisioning Information. Graphics Press, Cheshire, CT, USA, 1990. doi:https://doi.org/10.1017/ S0022112091210654.

[UFK*89] Upson C., Faulhaber T.A. J., Kamins D., Laidlaw D., Schlegel D., VRoom J., Gurwitz R., DAm A. V.: The application visualization system: a computational environment for scientific visualization. IEEE Computer Graphics and Applications 9, 4 (1989). doi:10.1109/38.31462.

[War94] WARD M. O.: Xmdvtool: integrating multiple methods for visualizing multivariate data. In Proceedings IEEE Conference on Visualization (Oct 1994), pp. 326-333. doi : 10.1109/VISUAL. 1994. 346302 .

[War97] WARD M. O.: Creating and manipulating n-dimensional brushes. In Proceedings of Joint Statistical Meeting (1997), pp. 6-14.

[WBE*06] Weiskopf D., Borchers M., ERTL T., FAlK M., Fechtig O., Frank R., Grave F., King A., Kraus U., Muller T., Nollert H. P., Mendez I. R., Ruder H., Schafhitzel T., SCHAR S., ZAHN C., ZATLOUKAL M.: Explanatory and illustrative visualization of special and general relativity. IEEE Transactions on Visualization and Computer Graphics 12, 4 (July 2006), 522-534. doi:10.1109/TVCG.2006.69.

[WBG*12] Westoby M., Brasington J., Glasser N., Hambrey M., REYNOLDS J.: 'structure-from-motion' photogrammetry: A lowcost, effective tool for geoscience applications. Geomorphology 179 (2012), 300-314. doi:10.1016/j.geomorph.2012.08.021.

[WBWK00] WANG BALdONADO M. Q., WoOdRUFF A., KUCHINSKY A.: Guidelines for using multiple views in information visualization. In 
Proceedings of the Working Conference on Advanced Visual Interfaces (New York, NY, USA, 2000), AVI '00, ACM, pp. 110-119. doi:10. $1145 / 345513.345271$.

[Wea04] WEAVER C.: Building highly-coordinated visualizations in improvise. In IEEE Symposium on Information Visualization (2004), pp. 159-166. doi:10.1109/INFVIS.2004.12.

[Wea08] WEAVER C.: Multidimensional visual analysis using crossfiltered views. In 2008 IEEE Symposium on Visual Analytics Science and Technology (Oct 2008), pp. 163-170. doi:10.1109/VAST.2008. 4677370 .

[Wea10] WEAVER C.: Cross-filtered views for multidimensional visual analysis. IEEE Transactions on Visualization and Computer Graphics 16, 2 (March 2010), 192-204. doi:10.1109/TVCG.2009.94.

[WLY*14] WU Y., LIU S., YAN K., LIU M., WU F.: Opinionflow: Visual analysis of opinion diffusion on social media. IEEE Transactions on Visualization and Computer Graphics 20, 12 (Dec 2014), 1763-1772. doi:10.1109/TVCG.2014.2346920.

[Zak17] ZAKHAROV V.: Evaluation and combining association measures for collocation extraction. In Proceedings of the International Conference IMS-2017 (New York, NY, USA, 2017), IMS2017, ACM, pp. 125134. doi:10.1145/3143699.3143717.

[ZCCB12] ZhaO J., Chevalier F., Collins C., Balakrishnan R.: Facilitating discourse analysis with interactive visualization. IEEE Transactions on Visualization and Computer Graphics 18, 12 (Dec 2012), 2639-2648. doi:10.1109/TVCG.2012.226.

[ZKL*13] Zhang J., KANG K., LiU D., YUAN Y., E. Y.: Vis4heritage: Visual analytics approach on grotto wall painting degradations. IEEE Transactions on Visualization and Computer Graphics 19, 12 (Dec 2013), 1982-1991. doi:10.1109/TVCG.2013.219. 